(1)

\title{
Endocrine effects of duodenal-jejunal exclusion in obese patients with type 2 diabetes mellitus
}

\author{
Petra Kaválková1, Miloš Mráz², Pavel Trachta², Jana Kloučková1, Anna Cinkajzlová1, \\ Zdeňka Lacinová1,2, Denisa Haluzíková3, Marek Beneš4, Zuzana Vlasáková5, \\ Václav Burda6, Daniel Novák6, Tomáš Petr1, Libor Vítek1,7, Terezie Pelikánová5 and \\ Martin Haluzík ${ }^{1,8}$

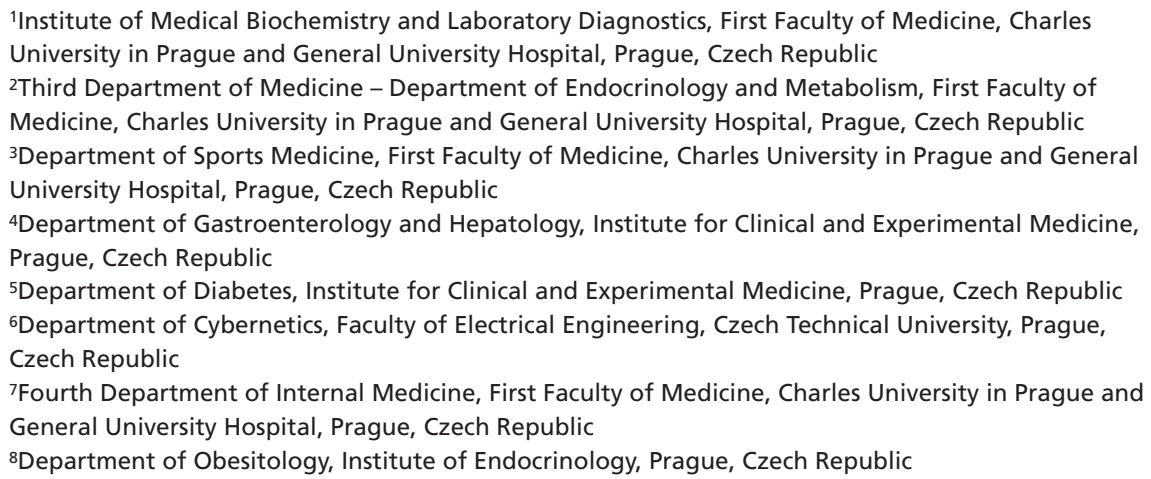

Correspondence should be addressed to M Haluzík Email mhalu@If1.cuni.cz

\begin{abstract}
Duodenal-jejunal bypass liner (DJBL) is an endoscopically implantable device designed to noninvasively mimic the effects of gastrointestinal bypass operations by excluding the duodenum and proximal jejunum from the contact with ingested food. The aim of our study was to assess the influence of DJBL on anthropometric parameters, glucose regulation, metabolic and hormonal profile in obese patients with type 2 diabetes mellitus (T2DM) and to characterize both the magnitude and the possible mechanisms of its effect. Thirty obese patients with poorly controlled T2DM underwent the implantation of DJBL and were assessed before and 1, 6 and 10 months after the implantation, and 3 months after the removal of DJBL. The implantation decreased body weight, and improved lipid levels and glucose regulation along with reduced glycemic variability. Serum concentrations of fibroblast growth factor 19 (FGF19) and bile acids markedly increased together with a tendency to restoration of postprandial peak of GLP1. White blood cell count slightly increased and red blood cell count decreased throughout the DJBL implantation period along with decreased ferritin, iron and vitamin B12 concentrations. Blood count returned to baseline values 3 months after DJBL removal. Decreased body weight and improved glucose control persisted with only slight deterioration 3 months after DJBL removal while the effect on lipids was lost. We conclude that the implantation of DJBL induced a sustained reduction in body weight and improvement in regulation of lipid and glucose. The increase in FGF19 and bile acids levels could be at least partially responsible for these effects.
\end{abstract}

\footnotetext{
Key Words

type 2 diabetes mellitus

- obesity

- duodenal-jejunal bypass liner

- bile acids

- fibroblast growth factor 19
} 


\section{Introduction}

The worldwide obesity epidemic together with related pathologies such as type 2 diabetes mellitus (T2DM) and increased risk of cardiovascular mortality and morbidity has underscored the need for effective, reliable and simple weight-reduction strategies (O'Rahilly 1997, Reaven et al. 2004). Despite intensive efforts, the search for a pharmacological approach able to effectively decrease body weight and improve metabolic complications still continues. The only strategy proven to induce sustainable reduction of body weight in patients with a high degree of obesity remains surgical treatment (Sjostrom et al. 2007, Pories 2008). Although major metabolic improvements are evident in all patients after bariatric surgery, various types of operations differ in the rate of diabetes remission and in the timing of metabolic improvements (Dixon et al. 2012).

Roux-en-Y gastric bypass represents the most frequently used bariatric procedure worldwide (Nannipieri et al. 2013). This operation combines the restrictive element (creation of a small stomach pouch) with its connection to the medium part of jejunum, so that the food bypasses the distal stomach, duodenum and proximal jejunum (the malabsorptive component). Numerous studies have documented multiple positive metabolic effects of gastric bypass, in particular the improvement in glucose control or even a complete diabetes remission that occur early after operation and are at least partially independent of weight loss (Cummings 2009). Although gastric bypass is an effective and durable approach to target both obesity and T2DM, it is still a major surgical procedure with all its limitations including the risk of perioperative or postoperative complications and also its irreversibility. Therefore, considerable efforts have been made to mimic the effects of gastric bypass using less invasive and reversible approaches.

Duodenal-jejunal bypass liner (DJBL) is an endoscopically implantable device designed to noninvasively mimic the effects of gastrointestinal bypass operations (Patel et al. 2012). It is a $60 \mathrm{~cm}$ long impermeable fluoropolymer sleeve that can be implanted endoscopically into the small intestine for up to 12 months (Rohde et al. 2016). The ingested food passes through the proximal part of small intestine (duodenum, proximal jejunum) through the impenetrable liner, which prevents its contact with intestinal wall. Less digested food then directly reaches the medium part of jejunum. Both the exclusion of the proximal part of small intestine and the presence of less digested food in its distal parts are thought to be at least partially responsible for the weight loss and improvement in diabetes control that have been described in obese patients with T2DM after DJBL implantation (Cohen et al. 2013). Nevertheless, the exact mechanisms responsible for these improvements and their reversibility after DJBL removal have not been rigorously explored and remain only partially understood.

We hypothesized that the effects of DJBL might be mediated through the changes of intestinal regulation of bile acids and fibroblast growth factor 19 (FGF19). To this end, we comprehensively studied the effect of 10 months of DJBL implantation on body composition, glucose control, and fasting and post-meal metabolic and hormonal profiles of subjects with obesity and poorly controlled T2DM. Furthermore, we explored the sustainability of different effects of DJBL 3 months after its removal.

\section{Materials and methods}

\section{Study subjects and intervention}

Thirty subjects (20 men and 10 women, aged 33-65 years) with obesity and T2DM having body mass index (BMI) $\geq 30 \mathrm{~kg} / \mathrm{m}^{2}$ and $\mathrm{HbA}_{1 \mathrm{c}} \geq 53 \mathrm{mmol} / \mathrm{mol}$ were included in the study. Their body weight and antidiabetic treatment were stable for at least 3 months before the beginning of the study. Study subjects were treated with diet only, oral antidiabetics only or a combination of oral antidiabetics and insulin. The mean duration of diabetes was $13.0 \pm 4.2$ years.

None of the studied subjects suffered from any other endocrine disorder and/or acute infectious disease and/or malignant tumor. Exclusion criteria included the use of incretin-based therapies 3 months before inclusion, acute cardiovascular disorder in the last 6 months, inability to discontinue antiaggregation therapy, severely impaired renal function with eGFR $0.5 \mathrm{~mL} / \mathrm{s}$ according to MDRD, severe liver impairment and history of bariatric surgery.

Written informed consent was provided by all participants before being enrolled in the study. The study was approved by the Human Ethics Review Board, First Faculty of Medicine, Charles University and General University Hospital, Prague, Czech Republic. The study protocol conformed to the ethical guidelines of the 1975 Declaration of Helsinki.

All participants underwent endoscopic implantation of DJBL, which was then kept in place for 10 months. They were examined before (Visit 1), and 1 month (Visit 2), 6 months (Visit 3) and 10 months (Visit 4)

Published by Bioscientifica Ltd. 
after DJBL implantation, respectively. Twenty-eight participants were also examined 3 months after DJBL removal (Visit 5). The remaining two subjects were not willing to return for the final visit, but upon phone contact they were found to be alive and in good condition.

\section{Anthropometric examination, blood sampling and continuous glucose monitoring}

All subjects underwent anthropometric examination and casual blood pressure measurement on every visit (V1-5). BMI was calculated using standard formula weight $(\mathrm{kg}) /$ height $(\mathrm{m})^{2}$. Blood samples for biochemical and hormonal measurements were taken after an overnight fasting and centrifuged for $10 \mathrm{~min}$ at $1000 \boldsymbol{g}$ within $30 \mathrm{~min}$ after withdrawal. Serum or plasma aliquots were subsequently stored at $-80^{\circ} \mathrm{C}$.

All subjects underwent mixed liquid meal test (MLMT) on visits 1, 2, 4 and 5 to evaluate the changes in blood glucose, insulin, C-peptide and incretin hormones. Venous blood samples were drawn before the start of MLMT (time $0 \mathrm{~min}$ ) and subsequently at minute 5, 15, 30, 60, 90 and 120, respectively, after ingestion of a $200 \mathrm{~mL}$ (200 kcal) liquid meal (Fresubin Original/Vanilla, Fresenius Kabi Deutschland GmbH, Bad Homburg, Germany). MLMT started between 08:00 and 09:00 h after an overnight fasting. Blood samples were then separated by centrifugation for $10 \mathrm{~min}$ at $1000 \mathrm{~g}$ within $30 \mathrm{~min}$ from blood collection. Blood samples for the measurement of incretin levels were collected into special blood tubes with inhibitor cocktail consisting of a dipeptidyl peptidase 4 , esterase and other protease inhibitors (BD P800, Becton, Dickinson and Company, Franklin Lakes, NJ, USA). Serum and plasma were subsequently stored in aliquots at $-80^{\circ} \mathrm{C}$ until further analysis.

Continuous glucose monitoring (iPro2, Medtronic, Northridge, CA, USA) was performed for 7 days on visits $1,2,4$ and 5 .

The percentage of body fat and the amount of lean body mass were assessed by body composition measurement using Bodystat 1500 (Bodystat Ltd, Douglas, UK).

\section{DJBL implantation}

DJBL was successfully implanted in all 30 patients. During the implantation, 17 patients were under full anesthesia including tracheal intubation. The rest of the patients underwent the procedure under analgosedation by a combination of propofol and opiate. The mean procedure time for an implantation was $18 \mathrm{~min}$ (7-58 min).

No serious adverse events occurred during the study. Mild abdominal pain and nausea after implantation were experienced by $72 \%$ of patients during first 14 days after implantation, 33\% of patients during the first month and $10 \%$ of patients after 1 month. Four patients had to be hospitalized after implantation for 2 days due to nausea or vomiting or for blood sugar monitoring. All of them were discharged without any subsequent problems. The rest of the patients were discharged the following day after the procedure.

Table 1 Anthropometric, biochemical and hormonal characteristics at baseline (V1), during DJBL implantation (V2-V4) and 3 months after DJBL removal (V5).

\begin{tabular}{|c|c|}
\hline & V1 \\
\hline Number of subjects & 30 \\
\hline Body weight (kg) & $129.7 \pm 4.4^{a}$ \\
\hline Waist circumference $(\mathrm{cm})$ & $133.6 \pm 2.7$ \\
\hline Hip circumference (cm) & $132.8 \pm 3.5$ \\
\hline BMI $\left(k g / m^{2}\right)$ & $42.7 \pm 1.2$ \\
\hline Body fat mass (\%) & $40.2 \pm 1.22$ \\
\hline Body lean mass (kg) & $77.0 \pm 2.4$ \\
\hline Fasting glucose (mmol/L) & $12.3 \pm 0.7$ \\
\hline $\mathrm{HbA}_{1 \mathrm{c}}(\mathrm{mmol} / \mathrm{mol})$ & $75.0 \pm 3.4$ \\
\hline Total cholesterol (mmol/L) & $4.45 \pm 0.15$ \\
\hline Triglycerides (mmol/L) & $2.33 \pm 0.33$ \\
\hline HDL cholesterol (mmol/L) & $1.09 \pm 0.04$ \\
\hline LDL cholesterol (mmol/L) & $2.71 \pm 0.16$ \\
\hline Leptin (ng/mL) & $23.8 \pm 2.5$ \\
\hline CRP (mg/L) & $3.29 \pm 0.50$ \\
\hline
\end{tabular}

V2
30
$123.9 \pm 4.2^{a}$
$129.4 \pm 2.4^{a}$
$130.1 \pm 3.0$
$41.0 \pm 1.2^{a}$
$37.9 \pm 1.43$
$76.0 \pm 2.8$
$10.1 \pm 0.6^{a}$
$66.5 \pm 2.8^{a}$
$3.99 \pm 0.13^{a}$
$1.77 \pm 0.14$
$1.01 \pm 0.04^{a}$
$2.21 \pm 0.12^{a}$
$18.9 \pm 1.9 a$
$3.32 \pm 0.45$

\begin{tabular}{c}
\hline $\mathbf{V 3}$ \\
30 \\
$118.7 \pm 4.2^{a, b}$ \\
$125.6 \pm 2.6^{a, b}$ \\
$126.4 \pm 2.6^{a, b}$ \\
$39.0 \pm 1.2^{a, b}$ \\
$35.6 \pm 1.18^{a}$ \\
$76.0 \pm 2.5$ \\
$9.54 \pm 0.6 a$ \\
$58.4 \pm 2.8^{a}, b$ \\
$4.23 \pm 0.15$ \\
$1.86 \pm 0.16$ \\
$1.05 \pm 0.04$ \\
$2.35 \pm 0.13^{a}$ \\
$20.1 \pm 2.3^{a}$ \\
$2.83 \pm 0.44$ \\
\hline
\end{tabular}

$\mathbf{V 4}$
30
$117.3 \pm 4.3^{a, b}$
$124.0 \pm 2.7 a, b$
$126.2 \pm 2.8^{a, b}$
$38.4 \pm 1.1 a, b$
$35.8 \pm 2.61^{a}$
$78.3 \pm 2.5^{a}$
$8.45 \pm 0.5^{a, b}$
$55.4 \pm 2.5^{a, b}$
$3.90 \pm 0.15^{a, c}$
$1.65 \pm 0.15$
$1.04 \pm 0.05$
$2.15 \pm 0.12^{a}$
$19.3 \pm 2.4{ }^{a}$
$2.26 \pm 0.37^{a, b}$

\begin{tabular}{c}
\multicolumn{1}{c}{ V5 } \\
\multicolumn{1}{c}{28} \\
$120.3 \pm 4.5^{a, b}$ \\
$124.3 \pm 2.2^{a, b}$ \\
$123.2 \pm 2.3^{a, b}$ \\
$39.0 \pm 0.9^{a, b}$ \\
$33.5 \pm 1.46^{a}$ \\
$74.3 \pm 3.5$ \\
$9.88 \pm 0.8^{a, d}$ \\
$61.1 \pm 3.3 a, b, d$ \\
$4.43 \pm 0.12^{b, d}$ \\
$2.34 \pm 0.64$ \\
$1.21 \pm 0.06^{a, b, c, d}$ \\
$2.48 \pm 0.10^{d}$ \\
$16.3 \pm 1.9^{a}$ \\
$1.67 \pm 0.28^{a, b, c}$ \\
\end{tabular}

Values are mean \pm S.E.M. Statistical significance is from one-way RM ANOVA or one-way RM ANOVA on ranks followed by Holm-Sidak test or Dunn's method. a $P<0.05$ vs V1, $\mathrm{b} P<0.05$ vs V2, $\mathrm{c} P<0.05$ vs V3, $\mathrm{d} P<0.05$ vs V4. BMI, body mass index, CRP, C-reactive protein.

http://joe.endocrinology-journals.org
DOI: $10.1530 / J O E-16-0206$
๑) 2016 Society for Endocrinology Printed in Great Britain
Published by Bioscientifica Ltd. 
After 10 months ( \pm 8 days) the explantation was carried out. Average time of the extraction was $15 \mathrm{~min}$ (6-66 min). All explantations were technically successful. Five patients underwent unplanned endoscopy for abdominal pain, dyspepsia and suspected upper gastrointestinal bleeding, all with negative results regarding bleeding or other acute complications.

Concerning dietary recommendations before, during and after DJBL implantation, patients were not instructed to specifically change their overall caloric intake throughout the study. Starting from 2 days before the implantation, all patients were put on liquid/mixed diabetic diet and remained on this diet until 1 month after the implantation. After V2 (1 month after implantation), the patients were allowed a regular diabetic diet according to nutritionist recommendations with the exclusion of big pieces of fibrous vegetables or fruits. After explantation of DJBL, no specific dietary restrictions were required (patients remained on diabetic diet).

\section{Hormonal and biochemical assays}

Biochemical parameters (glycemia, glycated hemoglobin $\mathrm{HbA}_{1 \mathrm{c}}$, total and HDL cholesterol, triglycerides and blood count) and macro- and micronutrients were measured by standard laboratory methods, and LDL cholesterol was calculated in the Department of Biochemistry of the General University Hospital, Prague, Czech Republic. Plasma active GLP1, GIP, leptin and insulin were measured by commercial multiplex assay (Human Metabolic Hormone Magnetic Bead Panel, HMHMAG-34K, Merck Millipore). Sensitivity was $1.2 \mathrm{pg} / \mathrm{mL}$ for active GLP1, $0.6 \mathrm{pg} / \mathrm{mL}$ for GIP, $87 \mathrm{pg} / \mathrm{mL}$ for insulin and $41 \mathrm{pg} / \mathrm{mL}$ for leptin. Glucagon was measured by commercial RIA kit
(GL-32K, MerckMillipore) with a sensitivity of $18.45 \mathrm{pg} / \mathrm{mL}$. Serum C-reactive protein (CRP) was measured by commercial instant ELISA kit (eBioscience, Bender MedSystems GmbH, Vienna, Austria), its sensitivity being 3 pg/mL. Human FGF21 and FGF19 were measured by commercial ELISA kits (BioVendor, Brno, Czech Republic). Sensitivity was $7 \mathrm{pg} / \mathrm{mL}$ for FGF21 and $4.8 \mathrm{pg} / \mathrm{mL}$ for FGF19, respectively. Intra- and interassay variabilities for all methods were $<10$ and $<20 \%$, respectively. The homeostasis model assessment (HOMA) was calculated according to formula: (fasting serum insulin $(\mathrm{mIU} / \mathrm{L}) \times$ fasting glucose $(\mathrm{mmol} / \mathrm{L})) / 22.5$.

Plasma bile acids concentrations were measured by gas chromatography/mass spectroscopy (GC/MS; Agilent 5973 Network Mass Selective Detector, 6890N Network GC System, Santa Clara, CA, USA) as described previously (Setchell \& Vestal 1989). Bile acids along with internal standard (23,24-bisnor-3bOH 5 a cholic acid, Steraloids Inc, Newport, RI, USA) were extracted from serum samples using SXG C18 columns (Tessek, Prague, Czech Republic); their conjugates were hydrolyzed by $10 \% \mathrm{KOH}$ and acidified by $10 \mathrm{M} \mathrm{HCl}$. The bile acids were washed on SXG C18 columns and then converted onto methylsilyl derivatives. All GC analyses were performed on a capillary column (5\% phenylmethylpolysiloxane, HP5MS, $15 \mathrm{~m} \times 0.25 \mathrm{~mm}$ ID, $0.25 \mathrm{~mm}$, ValcoBond, VICI Valco Instruments, Houston, TX, USA) with MS detection (quadruple mass spectrometer operating in a negative mode). The sensitivity of this method was $0.1 \mathrm{mmol} / \mathrm{L}$ and the reproducibility was $6.4 \%$.

\section{Statistical analysis}

Statistical analysis was performed using SigmaStat 13.0 software (Jandel Scientific, San Rafael, CA, USA).

Table 2 The influence of DJBL implantation (V2-V4) and removal (V5) on fasting blood glucose, continuous glucose monitoring parameters and glucose variability expressed as standard deviation (s.D.) and casual blood pressure measured on visit 1, 2, 4 and 5 .

\begin{tabular}{|c|c|c|c|c|}
\hline & V1 & $\mathbf{V 2}$ & V4 & V5 \\
\hline Number of subjects & 27 & 24 & 24 & 16 \\
\hline Glucose (mmol/L) & $12.3 \pm 0.7$ & $10.1 \pm 0.6^{a}$ & $8.45 \pm 0.5^{a, b}$ & $9.88 \pm 0.8^{a, c}$ \\
\hline Insulin (pg/mL) & $961.0 \pm 111.0$ & $790.1 \pm 84.0^{a}$ & $767.2 \pm 85.0^{a}$ & $732.0 \pm 101.0^{a}$ \\
\hline HOMA index & $11.4 \pm 1.4$ & $7.67 \pm 0.9^{a}$ & $6.49 \pm 0.9 a$ & $8.76 \pm 1.8^{a}$ \\
\hline 24-h mean glucose (mmol/L) & $10.5 \pm 0.5$ & $9.49 \pm 0.5^{a}$ & $8.70 \pm 0.5^{a}$ & $9.91 \pm 0.5^{a}$ \\
\hline 24-h glucose variability (mmol/L) & $2.39 \pm 0.17$ & $1.89 \pm 0.14^{a}$ & $1.96 \pm 0.18^{a}$ & $2.44 \pm 0.28 \mathrm{a}, \mathrm{c}$ \\
\hline Morning SBP (mmHg) & $150.2 \pm 3.7$ & $145.9 \pm 3.0$ & $143.1 \pm 3.0^{a}$ & $143.6 \pm 2.5^{a}$ \\
\hline Morning DBP (mmHg) & $92.1 \pm 1.5$ & $88.2 \pm 1.8^{a}$ & $86.8 \pm 1.8^{a}$ & $87.5 \pm 1.7^{a}$ \\
\hline
\end{tabular}

Values are mean \pm S.E.M. Statistical significance is from one-way RM ANOVA or one-way RM ANOVA on ranks followed by Holm-Sidak test or Dunn's method. a $P<0.05$ vs V1, b $P<0.05$ vs V2, $c P<0.05$ vs V4. DBP, diastolic blood pressure; HOMA index, homeostasis model assessment; SBP, systolic blood pressure. 
Data are expressed as mean \pm s.E.M. (standard error of the mean). One-way RM ANOVA or one-way RM ANOVA on ranks was used for the comparisons of anthropometric examinations, serum or plasma biochemical and hormonal parameters before and after implantation and after extraction of DJBL. Post hoc analyses were performed by Holm-Sidak test and Dunn's method. Blood glucose, insulin, C-peptide, incretin and bile acids levels at different time points $(0,15,30,60,90$ and $120 \mathrm{~min})$ during MLMT were analyzed on V1, 2, 4 and 5 using oneway RM ANOVA or one-way RM ANOVA on ranks and post hoc Holm-Sidak test or Dunn's method. Area under the concentration-time curves (AUCs) from 0 to $120 \mathrm{~min}$ were calculated using the trapezoidal rule. Standard deviation (s.D.) calculated from continuous glucose monitoring data was selected as the primary measure of glycemic variability. Statistical significance was assigned to $P<0.05$.

\section{Results}

\section{Influence of DJBL on anthropometric and biochemical parameters}

The baseline characteristics of study subjects are shown in Table 1 (column V1). As per inclusion criteria, all patients had poorly controlled T2DM with a mean $\mathrm{HbA}_{1 \mathrm{c}}$ of $75.0 \pm 3.36 \mathrm{mmol} / \mathrm{mol}$ and fasting blood glucose of $12.3 \pm 0.74 \mathrm{mmol} / \mathrm{L}$. The mean BMI was $42.7 \pm 1.22 \mathrm{~kg} / \mathrm{m}^{2}$ and the lipid levels were above the recommended lipid control values for patients with T2DM.

The DJBL implantation decreased body weight, waist and hip circumference and body fat mass (\%) with majority of significant changes starting from V2 (1 month after implantation) and further progressing throughout the 10-month follow-up (Table 1). At the end of the study period, all subjects experienced some degree of weight reduction that reached from 1.8 to $31.2 \%$, with $40 \%$ (12 subjects) achieving a decrease in
$>10 \%$ from initial body weight (average weight loss baseline vs 10 months $15.5 \pm 6.3$ vs $5.5 \pm 2.5 \%$ of BMI, $P<0.001$ for achievers vs nonachievers). Total cholesterol, LDL cholesterol, triglycerides and serum leptin levels were also decreased after DJBL implantation with a time pattern similar to anthropometric values. CRP, a marker of subclinical inflammation, did not change until V3, but it was significantly lowered at V4 (10 months after DJBL implantation).

To test the possible longer-term durability of DJBL after its removal, 28 out of 30 patients were examined 3 months after DJBL removal. There was a slight increase in body weight and $\mathrm{HbA}_{1 \mathrm{c}}$, but both the anthropometric and glucose control parameters were markedly below the baseline values (Table 1). $33.3 \%$ of the 10-percentreduction achievers experienced further weight loss, while this was the case only in $20 \%$ of the nonachievers. However, average weight regain 3 months after extraction did not differ between both groups $(3.8 \pm 3.3$ vs $2.9 \pm 1.9 \%$ of initial BMI, $P=0.417$ for achievers vs nonachievers). In contrast to $\mathrm{BMI}$ and $\mathrm{HbA}_{1 \mathrm{c}}$, total cholesterol, LDL cholesterol and triglycerides returned to baseline values, while CRP further decreased compared with V4. HDL concentrations significantly increased relative to $\mathrm{V} 4$ values.

\section{Influence of DJBL on glucose variability and blood pressure}

We performed continuous glucose monitoring at baseline (V1); 1 month (V2) and 10 months (V4) after DJBL implantation; 3 months after its removal (V5); and casual morning blood pressure measurement at each visit. DJBL implantation significantly reduced glucose variability expressed as SD starting from V1 throughout the entire DJBL implantation period (Table 2). This effect was completely lost at V5 3 months after DJBL removal. Casual systolic and diastolic blood pressure significantly decreased

Table 3 Effect of DJBL implantation and removal on blood count parameters.

\begin{tabular}{|c|c|c|}
\hline & v1 & V2 \\
\hline Number of subjects & 30 & 30 \\
\hline Leukocytes (109/L) & $7.70 \pm 0.34$ & $7.31 \pm 0.28$ \\
\hline Erythrocytes (1012/L) & $4.74 \pm 0.08$ & $4.56 \pm 0.07 a$ \\
\hline Hemoglobin (g/L) & $142.1 \pm 2.3$ & $135.4 \pm 2.4^{a}$ \\
\hline Hematocrit (\%) & $0.43 \pm 0.01$ & $0.41 \pm 0.01^{a}$ \\
\hline $\operatorname{MCV}(f l)$ & $91.0 \pm 1.0$ & $90.2 \pm 1.0$ \\
\hline
\end{tabular}

\begin{tabular}{c}
\hline V3 \\
\hline 30 \\
$8.62 \pm 0.26^{\mathrm{a}, \mathrm{b}}$ \\
$4.73 \pm 0.08^{\mathrm{b}}$ \\
$137.3 \pm 2.7^{\mathrm{a}}$ \\
$0.42 \pm 0.01^{\mathrm{a}}$ \\
$89.1 \pm 1.0^{\mathrm{a}, \mathrm{b}}$ \\
\hline
\end{tabular}

\begin{tabular}{c}
\hline $\mathbf{V 4}$ \\
\hline 30 \\
$8.11 \pm 0.32^{\mathrm{b}, \mathrm{c}}$ \\
$4.68 \pm 0.08^{\mathrm{b}}$ \\
$133.0 \pm 2.9^{\mathrm{a}, \mathrm{c}}$ \\
$0.41 \pm 0.01^{\mathrm{a}, \mathrm{c}}$ \\
$87.6 \pm 1.1^{\mathrm{a}, \mathrm{b}, \mathrm{c}}$ \\
\hline
\end{tabular}

\begin{tabular}{c}
\hline $\mathbf{V 5}$ \\
\hline 28 \\
$7.51 \pm 0.42^{c, d}$ \\
$4.91 \pm 0.10^{a, b, c, d}$ \\
$137.6 \pm 3.6^{a}$ \\
$0.42 \pm 0.01^{b, d}$ \\
$86.4 \pm 1.2^{a, b, c, d}$
\end{tabular}

Values are mean \pm S.E.M. Statistical significance is from one-way RM ANOVA or one-way RM ANOVA on ranks followed by Holm-Sidak test or Dunn's method. ${ }^{P}<0.05$ vs $V 1, b P<0.05$ vs V2, $c P<0.05$ vs V3, d $P<0.05$ vs $V 4$. $M C V$, mean erythrocyte volume.

http://joe.endocrinology-journals.org
DOI: $10.1530 / J O E-16-0206$
○ 2016 Society for Endocrinology Printed in Great Britain
Published by Bioscientifica Ltd 
starting at V3 (systolic) and V2 (diastolic) relative to V1 and the differences lasted throughout the implantation period and also 3 months after DJBL removal (Table 2).

\section{Influence of DJBL implantation on blood count}

The influence of DJBL implantation on blood count is shown in Table 3. DJBL implantation slightly but significantly increased white blood count (starting from V3) and decreased red blood count, hemoglobin and hematocrit (starting from V2), and mean erythrocyte volume (starting from V3). All changes with the exception of lower hemoglobin levels resolved at V5 3 months after DJBL removal.

\section{Influence of DJBL implantation on vitamins and trace elements}

The influence of DJBL implantation on vitamin and trace element concentrations is shown in Table 4. DJBL implantation decreased iron (starting from V2), zinc (starting from V3), vitamin B12 (starting from V3) and ferritin concentrations (starting from V3), whereas phosphorus levels were increased (starting from V3). No consistent changes in albumin, prealbumin, transferrin, magnesium, copper or zinc concentrations were detected. DJBL implantation did not significantly affect calcium, 1,25-dihydroxyvitamin D, vitamin A or vitamin E levels. Three months after DJBL removal, a significant increase in serum calcium, iron, zinc, albumin and prealbumin was found.

\section{Influence of DJBL implantation on hormonal parameters}

To shed more light on the possible mechanisms of action of DJBL, we measured numerous relevant hormonal parameters either as dynamic changes during the repeated meal tests at V1, 2, 4 and 5 or as fasting concentrations at the respective visits.

Fasting plasma insulin and C-peptide concentrations were decreased by DJBL implantation as were their levels in the 5thmin of the meal test (Fig. 1). The modified pattern of insulin curve was still present at V5 3 months after DJBL removal, while C-peptide levels were significantly lower in the 120th min of meal test at V5 compared with V4. Area under the curve for insulin was lower at V2 relative to V1 and returned to baseline values at V5 after DJBL removal. Area under the curve for C-peptide was lower at V4 relative to V1 and remained lower compared with V1 also at V5 after DJBL removal. $\mathrm{C}$-peptide V4 and V5 areas under the curve did not differ significantly.

Blood glucose levels were decreased by DJBL implantation at all the time points of the meal test starting from V1 1 month after DJBL implantation and increased slightly 3 months after DJBL removal (Fig. 1). The same was true for blood glucose AUC.

GLP1 concentrations during the meal test tended to increase at V2 and especially at V4, but the differences

Table 4 Effect of DJBL implantation (V2-V4) and removal (V5) on macro- and micronutrients.

\begin{tabular}{l}
\hline \\
\hline Number of subjects \\
Calcium $(\mathrm{mmol} / \mathrm{L})$ \\
Phosphorus $(\mathrm{mmol} / \mathrm{L})$ \\
Magnesium $(\mathrm{mmol} / \mathrm{L})$ \\
Iron $(\mu \mathrm{mol} / \mathrm{L})$ \\
Copper $(\mu \mathrm{mol} / \mathrm{L})$ \\
Zinc $(\mu \mathrm{mol} / \mathrm{L})$ \\
Vitamin $D$ total $(\mathrm{ng} / \mathrm{mL})$ \\
$1,25-D i h y d r o x y v i t a m i n ~ D ~(n g / L)$ \\
Vitamin A (mg/L) \\
Vitamin E $(\mathrm{mg} / \mathrm{L})$ \\
Vitamin B12 $(\mathrm{ng} / \mathrm{mL})$ \\
Folic acid $(\mu \mathrm{g} / \mathrm{mL})$ \\
Albumin $(\mathrm{g} / \mathrm{L})$ \\
Prealbumin $(\mathrm{g} / \mathrm{L})$ \\
Transferrin $(\mathrm{g} / \mathrm{L})$ \\
Ferritin $(\mu \mathrm{g} / \mathrm{L})$
\end{tabular}

\begin{tabular}{c}
$\mathbf{v 1}$ \\
\hline 30 \\
$2.24 \pm 0.02$ \\
$1.05 \pm 0.03$ \\
$0.70 \pm 0.02$ \\
$14.9 \pm 1.0$ \\
$18.9 \pm 0.7$ \\
$18.7 \pm 0.7$ \\
$16.0 \pm 1.4$ \\
$38.7 \pm 2.6$ \\
$0.68 \pm 0.06$ \\
$14.1 \pm 1.6$ \\
$375.8 \pm 23.6$ \\
$11.5 \pm 1.4$ \\
$43.8 \pm 0.5$ \\
$0.24 \pm 0.01$ \\
$3.06 \pm 0.10$ \\
$166.0 \pm 32.9$ \\
\hline
\end{tabular}

\begin{tabular}{c}
\hline V2 \\
\hline 30 \\
$2.22 \pm 0.02$ \\
$1.07 \pm 0.04$ \\
$0.65 \pm 0.02^{\mathrm{a}}$ \\
$10.8 \pm 0.56^{\mathrm{a}}$ \\
$19.0 \pm 0.7$ \\
$16.6 \pm 0.5^{\mathrm{a}}$ \\
$15.9 \pm 1.3$ \\
$41.6 \pm 3.2$ \\
$0.55 \pm 0.05$ \\
$11.6 \pm 1.4$ \\
$351.0 \pm 22.1$ \\
$15.6 \pm 6.4$ \\
$42.7 \pm 0.5^{\mathrm{a}}$ \\
$0.23 \pm 0.01^{\mathrm{a}}$ \\
$2.77 \pm 0.11^{\mathrm{a}}$ \\
$142.0 \pm 26.5$ \\
\hline
\end{tabular}

\begin{tabular}{c}
\hline $\mathbf{V 3}$ \\
\hline 30 \\
$2.27 \pm 0.02$ \\
$1.16 \pm 0.03^{\mathrm{a}, \mathrm{b}}$ \\
$0.69 \pm 0.02^{\mathrm{b}}$ \\
$11.1 \pm 0.7^{\mathrm{a}}$ \\
$20.0 \pm 0.6$ \\
$15.1 \pm 0.5^{\mathrm{a}, \mathrm{b}}$ \\
$17.9 \pm 1.8$ \\
$41.8 \pm 3.3$ \\
$0.53 \pm 0.05$ \\
$11.1 \pm 1.0$ \\
$294.1 \pm 21.6^{\mathrm{a}, \mathrm{b}}$ \\
$12.0 \pm 1.4$ \\
$43.5 \pm 0.5$ \\
$0.24 \pm 0.01$ \\
$3.09 \pm 0.13^{\mathrm{b}}$ \\
$101.9 \pm 20.7^{\mathrm{a}, \mathrm{b}}$ \\
\hline
\end{tabular}

\begin{tabular}{c}
\hline $\mathbf{V 4}$ \\
\hline 30 \\
$2.21 \pm 0.03^{\mathrm{c}}$ \\
$1.17 \pm 0.03^{\mathrm{a}, \mathrm{b}}$ \\
$0.69 \pm 0.02^{\mathrm{b}}$ \\
$10.8 \pm 0.7^{\mathrm{a}}$ \\
$18.3 \pm 0.6^{\mathrm{c}}$ \\
$14.5 \pm 0.4^{\mathrm{a}, \mathrm{b}}$ \\
$13.7 \pm 1.4$ \\
$41.0 \pm 3.4$ \\
$0.48 \pm 0.05$ \\
$9.83 \pm 0.9$ \\
$276.2 \pm 18.4^{\mathrm{a}, \mathrm{b}}$ \\
$11.6 \pm 1.3$ \\
$41.3 \pm 0.6^{\mathrm{a}, \mathrm{b}, \mathrm{c}}$ \\
$0.23 \pm 0.01^{\mathrm{a}}$ \\
$3.12 \pm 0.13^{\mathrm{b}}$ \\
$72.5 \pm 14.2^{\mathrm{a}, \mathrm{b}}$ \\
\hline
\end{tabular}

\begin{tabular}{c}
\hline \multicolumn{1}{c}{ V5 } \\
\hline \multicolumn{1}{c}{28} \\
$2.31 \pm 0.01^{\mathrm{a}, \mathrm{b}, \mathrm{d}}$ \\
$1.17 \pm 0.04^{\mathrm{a}, \mathrm{b}}$ \\
$0.72 \pm 0.02^{\mathrm{b}, \mathrm{d}}$ \\
$13.2 \pm 1.1^{\mathrm{b}, \mathrm{c}, \mathrm{d}}$ \\
$18.1 \pm 0.6^{\mathrm{c}}$ \\
$16.1 \pm 0.5^{\mathrm{a}, \mathrm{d}}$ \\
$16.0 \pm 1.4$ \\
$37.4 \pm 3.1$ \\
$0.57 \pm 0.05$ \\
$12.4 \pm 0.89$ \\
$303.8 \pm 27.0^{\mathrm{a}, \mathrm{b}}$ \\
$9.89 \pm 0.7$ \\
$44.1 \pm 0.5^{\mathrm{b}, \mathrm{d}}$ \\
$0.26 \pm 0.01^{\mathrm{a}, \mathrm{b}, \mathrm{c}, \mathrm{d}}$ \\
$3.15 \pm 0.15^{\mathrm{b}}$ \\
$76.1 \pm 17.4^{\mathrm{a}, \mathrm{b}, \mathrm{c}}$ \\
\hline
\end{tabular}

Values are mean \pm S.E.M. Statistical significance is from one-way RM ANOVA or one-way RM ANOVA on ranks followed by Holm-Sidak test or Dunn's method. ${ }^{a} P<0.05$ vs $\mathrm{V} 1,{ }^{b} P<0.05$ vs $\mathrm{V} 2,{ }^{c} P<0.05$ vs V3, ${ }^{d} P<0.05$ vs $V 4$. 
A-1

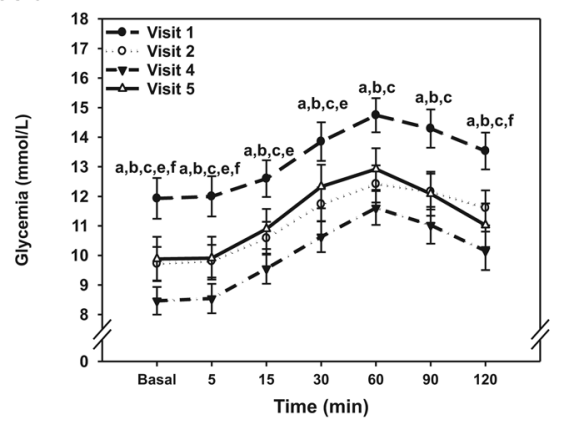

B-1
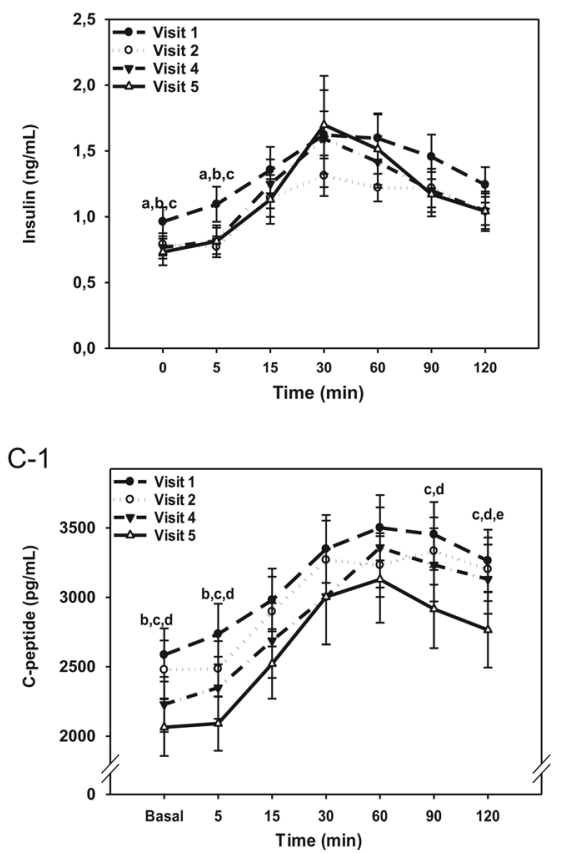

A-2

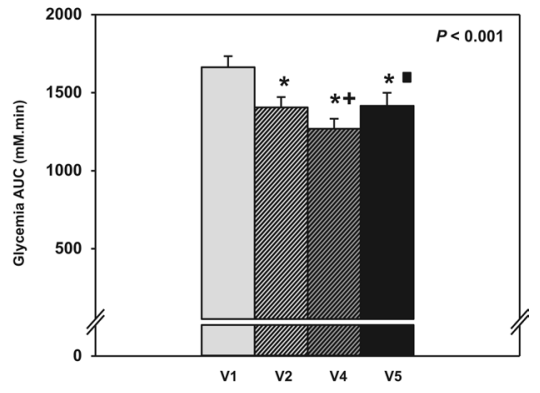

B-2
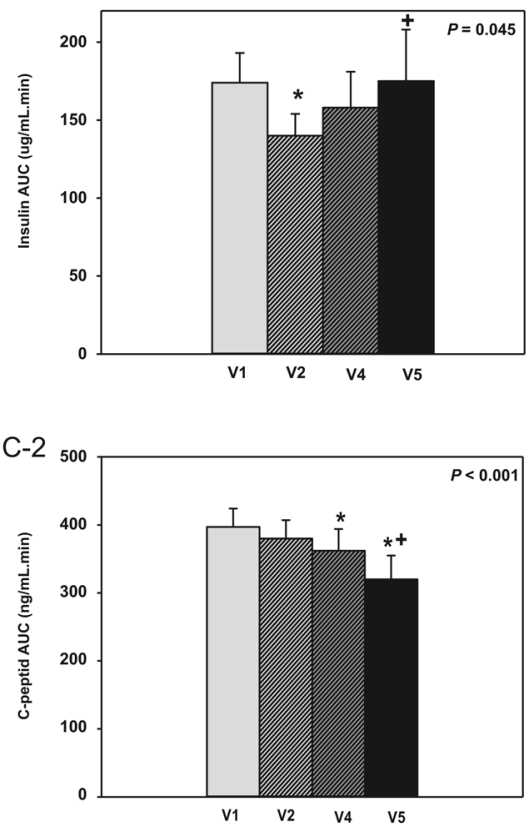

Figure 1

The influence of DJBL implantation (V2-V4) and removal (V5) on blood glucose (panel A-1, panel A-2), insulin (panel B-1, panel B-2) and C-peptide (panel $\mathrm{C}-1$, panel $\mathrm{C}-2$ ) levels at different time points $(0,15,30,60,90$ and $120 \mathrm{~min})$ during mixed liquid meal test. Values are mean \pm S.E.M. Statistical significance is from one-way RM ANOVA or one-way RM ANOVA on ranks followed by Holm-Sidak test or Dunn's method. A/B/C-1: a $P<0.05$ V1 vs V2; ${ }^{\circ} P<0.05$ V1 vs V4; $c P<0.05$ V1 vs V5; $d P<0.05$ V2 vs V5; $P<<0.05$ V4 vs V5; ${ }^{\mathrm{f} P}<0.05$ V2 vs $\mathrm{V} 4$. $\mathrm{A} / \mathrm{B} / \mathrm{C}-2$ : ${ }^{*} P<0.05$ vs V1; $+P<0.05$ vs V2; ${ }^{\circ} P<0.05$ vs V3; $\square<<0.05$ vs V4. relative to $\mathrm{V} 1$ did not reach statistical significance owing mostly to the relatively high variability of its levels (Fig. 2). The GLP1 levels 3 months after DJBL removal returned to baseline values.

Plasma glucagon levels during the meal test were decreased at V2 relative to baseline with similar, albeit statistically nonsignificant, pattern at V4 (Fig. 2). At V5, glucagon levels returned to baseline values. The glucagon AUC followed the same pattern.

Peak plasma GIP concentrations at 30thmin of the meal test were reduced at V4 10 months after DLBL implantation relative to $\mathrm{V} 1$ and returned to baseline values at V5 3 months after DJBL removal (Fig. 2). The AUC for GIP did not significantly differ throughout the study.

Serum thyroid-stimulating hormone (TSH) concentrations were not affected by DJBL implantation (data not shown).

\section{Influence of DJBL implantation on FGF19, FGF21 and bile acid levels}

To further study the mechanism of action of DJBL on glucose metabolism, we measured total plasma bile acid and FGF19 levels during the meal tests at V1, 2, 4 and 5 (in 10 out of 30 patients) and fasting concentrations of FGF19 and FGF21 at all visits. Plasma bile acid levels significantly increased only at 5thmin at V2 (1 month after DJBL implantation), but were markedly increased throughout all but baseline time point at V4 10months after DJBL implantation (Fig. 3). These changes were completely lost at V5 3 months after DJBL removal. The bile acid AUC was increased at V4 relative to V1 and returned to baseline values at V5.

Fasting FGF19 concentrations increased at V2 and remained elevated throughout the DJBL implantation (Fig. 3). This difference was blunted after DJBL removal.

Published by Bioscientifica Ltd. 
A-1

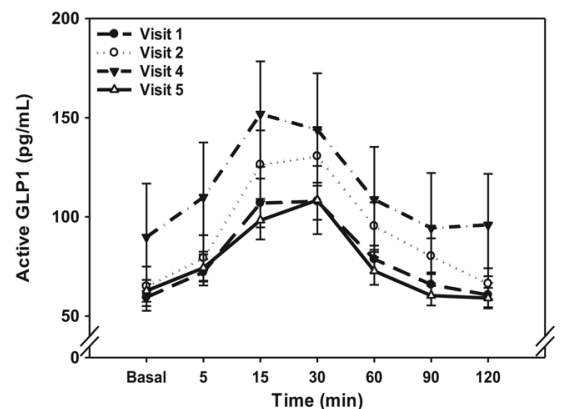

B-1

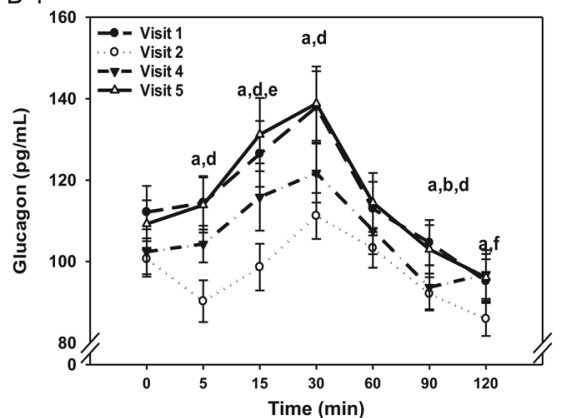

C-1

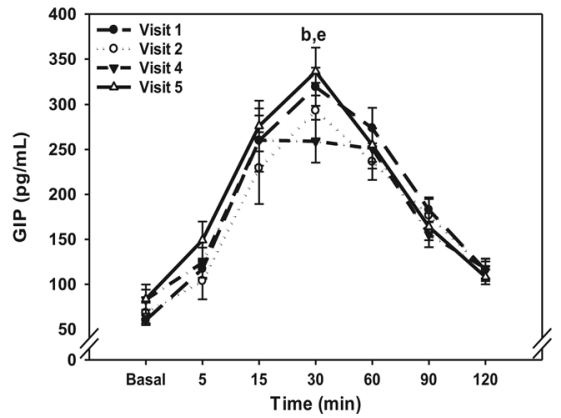

A-2

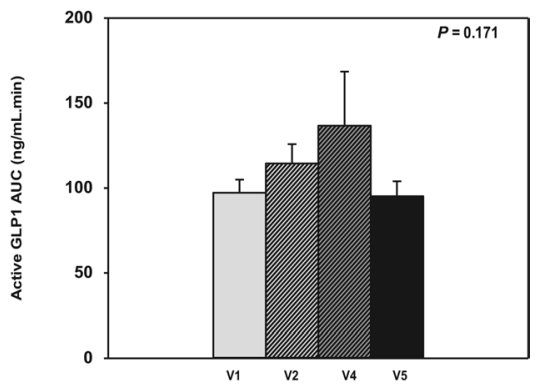

B-2

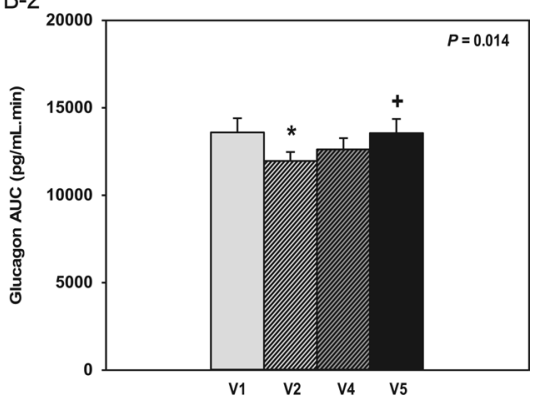

C-2

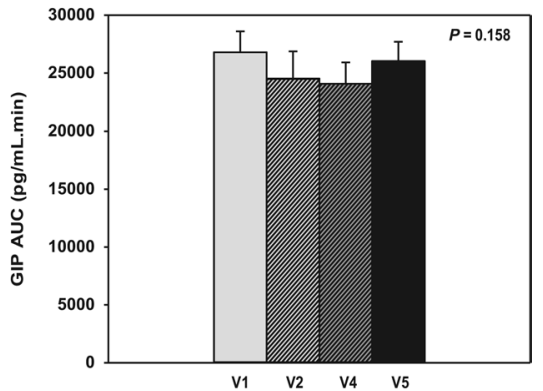

Figure 2

The influence of DJBL implantation (V2-V4) and removal (V5) on plasma active GLP1 (panel A-1, panel A-2), glucagon (panel B-1, panel B-2) and GIP (panel C-1, panel C-2) levels during mixed liquid meal test at different time points $(0,15$, $30,60,90$ and $120 \mathrm{~min})$. Values are mean \pm S.E.M. Statistical significance is from one-way RM ANOVA or one-way RM ANOVA on ranks followed by Holm-Sidak test or Dunn's method. A/B/C-1: a $P<0.05$ V1 vs V2; b $P<0.05$ V1 vs V4 $\mathrm{d} P<0.05$ V2 vs V4; $\mathrm{e} P<0.05$ V4 vs V5. A-2/B-2/C-2: $* P<0.05$ vs $\mathrm{V} 1 ;+P<0.05$ vs $\mathrm{V} 2$.
The pattern of FGF19 curve during the meal test was not significantly affected by DJBL implantation (Fig. 3). FGF21 levels were not affected by DJBL implantation or its removal (data not shown).

\section{Changes in antidiabetic, antihypertensive and hypolipidemic medication after DJBL implantation}

At baseline, one subject (3.33\%) was on diet only; others were treated with oral antidiabetic drugs (33.3\%), insulin (3.33\%) or their combination (60\%). The number of patients treated with either basal or prandial insulin or metformin did not change significantly throughout the study (63.3 vs 66.7 vs $64.3 \%$ of subjects, n.s. for V1 vs V4 vs V5 for basal insulin; 46.7 vs 46.7 vs $50.0 \%$ of subjects, n.s. for prandial insulin; 93.3 vs 86.7 vs $89.3 \%$ of subjects, n.s. for metformin). Nevertheless, DJBL implantation tended to decrease both the basal (24.5 \pm 4.5 vs $20.9 \pm 4.2 \mathrm{IU} /$ day for $\mathrm{V} 1$ vs $\mathrm{V} 4, P=0.089)$ and prandial insulin dose $(17.0 \pm 4.1$ vs $12.3 \pm 2.8 \mathrm{IU} /$ day for $\mathrm{V} 1$ vs $\mathrm{V} 4$, $P=0.146)$, although the difference did not reach statistical significance. Interestingly, this trend persisted even after DJBL extraction (basal insulin 19.5 $\pm 4.0 \mathrm{IU} /$ day, $P=0.074$ vs V1; prandial insulin $12.3 \pm 3.0 \mathrm{IU} /$ day, $P=0.080$ vs V1). A similar situation could be seen with metformin $(2317.2 \pm 159.6$ vs $2137.9 \pm 198.4 \mathrm{mg} /$ day for $\mathrm{V} 1$ vs $\mathrm{V} 4$, $P=0.203 ; 1963.0 \pm 231.0 \mathrm{mg} /$ day for V5, $P=0.054 \mathrm{vs} \mathrm{V1})$. At the end of the implantation period, basal insulin dose was reduced in 11 (57.9\%) and increased in 5 (26.3\%) out of 19 subjects on initial basal insulin therapy, with 1 subject being started on de novo basal insulin during the study. The dosage of prandial insulin was decreased in 9 (64.3\%) out of 14 subjects while increasing in 2 (14.3\%) and being newly introduced in 2 previously prandial insulin-naïve 

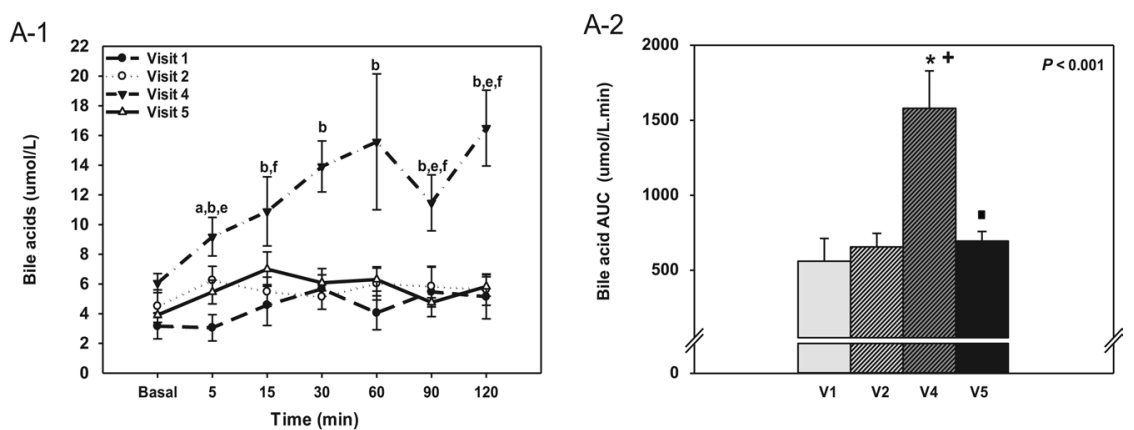

B

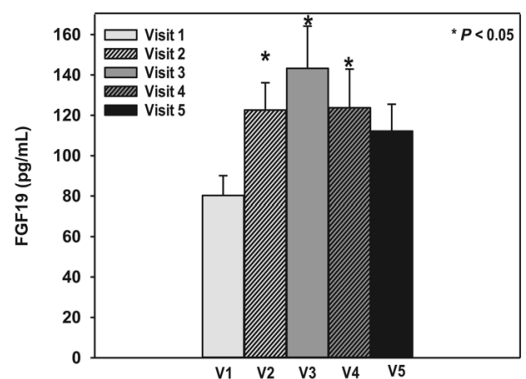

B-1

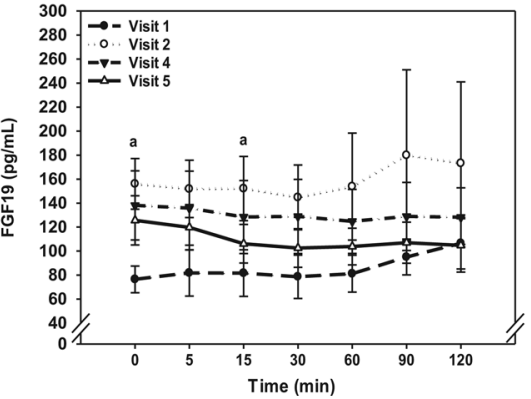

B-2

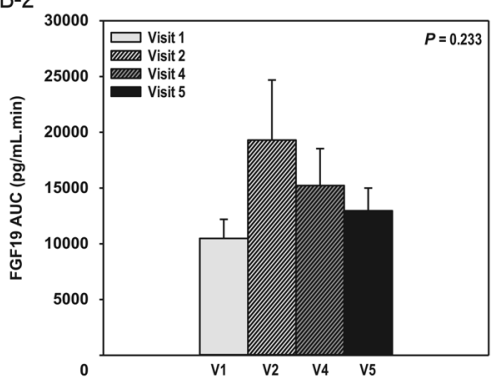

Figure 3

The influence of DJBL implantation (V2-V4) and removal (V5) on bile acids levels during mixed liquid meal test (panels A-1 and A-2), fasting plasma FGF19 concentrations (panel B) and FGF19 concentrations during mixed liquid meal test (panels B-1 and B-2). Values are mean \pm s.E.M. Statistical significance is from one-way RM ANOVA or one-way RM ANOVA on ranks followed by Holm-Sidak test or Dunn's method. $\mathrm{A} / \mathrm{B}-1$ : $\mathrm{a} P<0.05 \mathrm{~V} 1$ vs $\mathrm{V2}$; $\mathrm{b} P<0.05 \mathrm{~V} 1$ vs V4; e $P<0.05$ V4 vs V5; ${ }^{f} P<0.05$ V2 vs V4. A-2; B; B-2: ${ }^{*} P<0.05$ vs $\mathrm{V} 1 ;+P<0.05$ vs $\mathrm{V} 2 ; \square P<0.05$ vs $\mathrm{V} 4$. patients, whereas in 2 other subjects, prandial insulin was discontinued. In the course of the trial, antidiabetic treatment was completely discontinued in 2 subjects (both of them initially on metformin monotherapy) and this effect also persisted 3 months after DJBL removal.

No change in the number of subjects on antihypertensive medication was observed during the study period (90 vs 93.3 vs $85.7 \%$, n.s. for V1 vs V4 vs V5). The amount of individual antihypertensives increased in five subjects while it decreased in 4 other patients at V4 compared with V1. Similarly, DJBL implantation did not affect the use of lipid-lowering agents with $36.7 \%$ of subjects being on statins and $20 \%$ on fibrates throughout the study.

\section{Discussion}

In our study, DJBL implantation markedly improved glucose control, decreased glucose variability and reduced body weight in obese patients with poorly controlled type 2 diabetes mellitus. These improvements were accompanied by a significant and sustained increase in circulating fibroblast growth factor 19 and bile acid levels together with reduced postprandial glucagon levels.

The extent of decrease in $\mathrm{HbA}_{1 \mathrm{c}}$ and body weight in our study was higher than that in a recently published meta-analysis of studies with DJBL implantation, where the difference in $\mathrm{HbA}_{1 \mathrm{c}}(-0.9 \%)$ did not reach statistical significance (Rohde et al. 2016). The reason for the higher efficacy of DJBL in our study could have been rather poor glucose control and higher body weight of our study subjects at baseline. This may have favored a more profound effect of intervention as compared with patients with less pronounced obesity and better glucose control in some other studies. Also, the results of our study should be viewed in the context of a lacking control group undergoing sham procedure. Overall, both published data and our data suggest that the antidiabetic

Published by Bioscientifica Ltd. 
and weight-reducing efficacy of DJBL implantation is much lower compared with bariatric surgery.

The 'foregut' and 'hindgut hypotheses' have been put together in efforts to explain the positive metabolic effects of bariatric surgery (Dixon et al. 2012). These hypotheses may well apply to the mechanisms of metabolic improvements after DJBL. According to the foregut hypothesis, the exclusion of the proximal part of small intestine from nutrient passage may suppress the production of theoretically postulated, albeit hitherto unidentified, factors impairing insulin secretion and leading to other metabolic derangements (Rubino et al. 2006). The hindgut hypothesis suggests that expedited delivery of nutrients to the distal parts of small intestine promotes metabolic improvements and weight loss by the accentuation of the ileal brake (Maljaars et al. 2008). In our study, a tendency toward increased GLP1 secretion after DJBL implantation has been noted while we did not see consistent changes in GIP or in other gastrointestinal hormones produced in more distal parts of the intestine such as peptide YY (data not shown). Our GLP1 data are generally in agreement with previously described increases in GLP1 concentrations after DJBL implantation (de Jonge et al. 2013b). In contrast to our data, de Jonge and coworkers $(2013 b)$ found markedly decreased GIP levels during mixed meal test. Another study described increased postprandial concentrations of peptide YY and ghrelin combined with decreased cholecystokinin levels (de Jonge et al. 2016). Taken together, multiple changes in gastrointestinal hormones may contribute to positive metabolic effects of DJBL.

Although the modest tendency toward increased GLP1 is unlikely to explain the positive metabolic effects of DJBL implantation, a sustained increase in circulating bile acids and FGF19 found in our study offers a more complex picture. FGF19 is an important regulator of bile acid levels (Holt et al. 2003) with positive metabolic effects such as decreased body weight and improved glucose control demonstrated in experimental studies in mice (Tomlinson et al. 2002). Thus, its increase could directly contribute to improved diabetes control observed in our study, although it still remains to be seen whether such effects are indeed present in humans (Mraz et al. 2011). Nevertheless, some previous studies including our data have documented that metabolic improvements after selected types of bariatric operations are also accompanied by increased FGF19 levels (Gerhard et al. 2013, Haluzikova et al. 2013).

Bile acids have been proven to significantly contribute to the regulation of whole-body metabolism through the stimulation of TGR5 receptors (Kim et al. 2007, Penney et al. 2015, Vitek \& Haluzik 2016). Bile acid sequestrants are a treatment option for patients with T2DM, which is approved in the USA (Hansen et al. 2014). Increased bile acid signaling in the liver may explain improvements in glucose control including reduced glucose variability as well as decreased lipid levels after DJBL implantation. Glucagon, another important player in glucose regulation (Young 2005), was consistently reduced after DJBL implantation in our study suggesting its contribution to glucose control improvements. The mechanism behind decreased glucagon secretion probably includes the combination of increased GLP1 levels together with FGF19 and bile acids effects on glucagon secretion (McGavigan et al. 2015).

Another interesting finding noted in our study was a marked decrease in both systolic and diastolic blood pressure. This decrease occurred at 1 month after DJBL implantation for systolic and 3 months after DJBL implantation for diastolic blood pressure, respectively. Interestingly, blood pressure remained decreased at 3 months after DJBL removal. A possible mechanism responsible for decreased blood pressure may include the combination of weight loss and increased GLP1 levels through similar mechanisms suggested for GLP1 receptor agonists (Ussher \& Drucker 2014).

High glucose variability and in particular increased lipid levels were shown to markedly contribute to high cardiovascular risk of patients with T2DM (Arca 2007, Di Flaviani et al. 2011). Our study has demonstrated that DJBL implantation markedly decreased glucose variability as well as serum triglyceride and LDL concentrations. Decreased glucose variability could be attributed to a combination of decreased body weight, enhanced GLP1 secretion and delayed gastric emptying previously shown after DJBL implantation (de Moura et al. 2015). The improvement in lipid levels can be, in addition to beneficial effects of body weight reduction, explained also by both direct and indirect effects of increased bile acids (Spinelli et al. 2016) and direct action of FGF19 in the liver (Bhatnagar et al. 2009). Positive effects of DJBL implantation on the liver function were recently demonstrated in patients with fatty liver disease (de Jonge et al. 2013a).

Obesity and T2DM are accompanied by subclinical inflammation arising primarily in the visceral adipose tissue and contributing to both insulin resistance and accelerated atherosclerosis (Haffner 2003, Mraz \& Haluzik 2014). Weight loss induced by bariatric surgery typically improves subclinical inflammation on both the systemic and the adipose tissue level (Bluher 2012). In our study,

Published by Bioscientifica Ltd 
decreased body weight and improved glucose control after DJBL implantation did not result in reduced subclinical inflammation as measured by CRP levels during the first 6 months of the follow-up, which is in agreement with previously published data by de Jonge and coworkers (2014). In de Jonge's study, a transient elevation in proinflammatory cytokines TNFa and interleukin 6 was described 3 months after DJBL implantation. These levels returned to baseline 6 months after DJBL implantation. In our study, a significant decrease in CRP was detectable as late as after 10 months of DJBL implantation. Interestingly, further decrease in CRP levels was seen 3 months after DJBL removal despite a slight increase in body weight and worsening of diabetes control.

In our study, leukocyte count was significantly increased after DJBL implantation throughout the entire follow-up period and this increase disappeared after DJBL removal. This finding suggests the possibility of a local inflammatory response to DJBL implantation most probably in the tissues surrounding the fixating anchor of DJBL in duodenum. Interestingly, red blood cell count, and iron and ferritin concentrations were also reduced after DJBL implantation in our study. Since iron is primarily absorbed in the duodenum (Silva \& Faustino 2015), it is plausible to suggest that these changes are due to iron malabsorption owing to duodenum exclusion by DJBL. The exact etiology of decreased concentrations of vitamin B12 noted in our study is not clear. Taken together, our data suggest that thorough measurements of blood count, and iron and vitamin B12 levels in patients undergoing DJBL implantation might be necessary to detect and eventually substitute their deficiencies.

A possible durability of the effects of DJBL after its removal has been suggested. Previous studies have shown that after extraction of DJBL, body weight partially increases and glucose control slightly deteriorates, but some of its effects still persist (de Jonge et al. 2013b, Koehestanie et al. 2014). Here, we show that 3 months after its removal, DJBL-associated body weight reduction was still present with an average regain of $3 \mathrm{~kg}$ from $12 \mathrm{~kg}$ that was lost. Also, the significant improvement in glucose control mostly persisted while the positive effects on lipid levels as well as reduced glucose variability were lost. The explanation of the persistence of some but not all effects of DJBL after its extraction is not clear. It may include some lasting adaptive changes in intestinal mucosa or other mechanisms that need to be explored further.

Our study provides some novel information regarding the possible mechanism of action of DJBL. It is also important to mention the limitations of our study such as the lack of the sham control group, only 2-h duration of the meal test, measurement of total bile acids rather than its subfractions, and the fact that dynamic changes of bile acids and FGF19 during the meal test were measured only in a subset of patients.

In summary, the implantation of DJBL induced a sustained reduction in body weight and improvement in blood pressure, and regulation of lipids and glucose. The increase in FGF19 and bile acid levels, combined with reduced glucagon, could be at least partially responsible for these effects. The influence of DJBL on body weight and glucose control mostly persisted 3 months after its removal, while its positive effects on lipids and glucose variability were completely reversed.

\section{Declaration of interest}

The authors declare that there is no conflict of interest that could be perceived as prejudicing the impartiality of the research reported.

\section{Funding}

This work was supported by project no. NT14083-3/2013, AZV 15-27863A and RVO VFN64165 from the Ministry of Health of Czech Republic.

\section{References}

Arca M 2007 Atorvastatin efficacy in the prevention of cardiovascular events in patients with diabetes mellitus and/or metabolic syndrome. Drugs 67 43-54. (doi:10.2165/00003495-200767001-00005)

Bhatnagar S, Damron HA \& Hillgartner FB 2009 Fibroblast growth factor-19, a novel factor that inhibits hepatic fatty acid synthesis. Journal of Biological Chemistry 284 10023-10033. (doi:10.1074/ jbc.M808818200)

Bluher M 2012 Are there still healthy obese patients? Current Opinion in Endocrinology, Diabetes, and Obesity 19 341-346. (doi:10.1097/ MED.0b013e328357f0a3)

Cohen R, le Roux CW, Papamargaritis D, Salles JE, Petry T, Correa JL, Pournaras DJ, Galvao Neto M, Martins B, Sakai P, et al. 2013 Role of proximal gut exclusion from food on glucose homeostasis in patients with type 2 diabetes. Diabetic Medicine 30 1482-1486. (doi:10.1111/ dme.12268)

Cummings DE 2009 Endocrine mechanisms mediating remission of diabetes after gastric bypass surgery. International Journal of Obesity 33 S33-S40. (doi:10.1038/ijo.2009.15)

de Jonge C, Rensen SS, Koek GH, Joosten MF, Buurman WA, Bouvy ND \& Greve JW 2013a Endoscopic duodenal-jejunal bypass liner rapidly improves plasma parameters of nonalcoholic fatty liver disease. Clinical Gastroenterology and Hepatology 11 1517-1520. (doi:10.1016/ j.cgh.2013.07.029)

de Jonge C, Rensen SS, Verdam FJ, Vincent RP, Bloom SR, Buurman WA le Roux CW, Schaper NC, Bouvy ND \& Greve JW 2013b Endoscopic duodenal-jejunal bypass liner rapidly improves type 2 diabetes. Obesity Surgery 23 1354-1360. (doi:10.1007/s11695-013-0921-3)

de Jonge C, Rensen SS, D'Agnolo HM, Bouvy ND, Buurman WA \& Greve JW 2014 Six months of treatment with the endoscopic duodenal-jejunal bypass liner does not lead to decreased systemic inflammation in obese patients with type 2 diabetes. Obesity Surgery 24 337-341. (doi:10.1007/s11695-013-1154-1) 
de Jonge C, Rensen SS, Verdam FJ, Vincent RP, Bloom SR, Buurman WA, le Roux CW, Bouvy ND \& Greve JW 2016 Impact of duodenaljejunal exclusion on satiety hormones. Obesity Surgery 26 672-678. (doi:10.1007/s11695-015-1889-y)

de Moura EG, Lopes GS, Martins Bda C, Orso IR, Coutinho AM, de Oliveira SL, Sakai P, Galvao-Neto Mdos P, Santo MA, Sapienza MT, et al. 2015 Effects of duodenal-jejunal bypass liner (EndoBarrier®) on gastric emptying in obese and type 2 diabetic patients. Obesity Surgery 25 1618-1625. (doi:10.1007/s11695-015-1594-x)

Di Flaviani A, Picconi F, Di Stefano P, Giordani I, Malandrucco I, Maggio P, Palazzo P, Sgreccia F, Peraldo C, Farina F, et al. 2011 Impact of glycemic and blood pressure variability on surrogate measures of cardiovascular outcomes in type 2 diabetic patients. Diabetes Care $\mathbf{3 4}$ 1605-1609. (doi:10.2337/dc11-0034)

Dixon JB, le Roux CW, Rubino F \& Zimmet P 2012 Bariatric surgery for type 2 diabetes. Lancet 379 2300-2311. (doi:10.1016/S01406736(12)60401-2)

Gerhard GS, Styer AM, Wood GC, Roesch SL, Petrick AT, Gabrielsen J, Strodel WE, Still CD \& Argyropoulos G 2013 A role for fibroblast growth factor 19 and bile acids in diabetes remission after Roux-en-Y gastric bypass. Diabetes Care 36 1859-1864. (doi:10.2337/dc12-2255)

Haffner SM 2003 Insulin resistance, inflammation, and the prediabetic state. American Journal of Cardiology 92 18J-26J. (doi:10.1016/S00029149(03)00612-X)

Haluzikova D, Lacinova Z, Kavalkova P, Drapalova J, Krizova J, Bartlova M, Mraz M, Petr T, Vitek L, Kasalicky M, et al. 2013 Laparoscopic sleeve gastrectomy differentially affects serum concentrations of FGF-19 and FGF-21 in morbidly obese subjects. Obesity 21 1335-1342. (doi:10.1002/oby.20208)

Hansen M, Sonne DP \& Knop FK 2014 Bile acid sequestrants: glucoselowering mechanisms and efficacy in type 2 diabetes. Current Diabetes Reports 14 482. (doi:10.1007/s11892-014-0482-4)

Holt JA, Luo G, Billin AN, Bisi J, McNeill YY, Kozarsky KF, Donahee M, Wang DY, Mansfield TA, Kliewer SA, et al. 2003 Definition of a novel growth factor-dependent signal cascade for the suppression of bile acid biosynthesis. Genes \& Development 17 1581-1591. (doi:10.1101/ gad.1083503)

Kim I, Ahn SH, Inagaki T, Choi M, Ito S, Guo GL, Kliewer SA \& Gonzalez FJ 2007 Differential regulation of bile acid homeostasis by the farnesoid X receptor in liver and intestine. Journal of Lipid Research 48 2664-2672. (doi:10.1194/jlr.M700330-JLR200)

Koehestanie P, de Jonge C, Berends FJ, Janssen IM, Bouvy ND \& Greve JW 2014 The effect of the endoscopic duodenal-jejunal bypass liner on obesity and type 2 diabetes mellitus, a multicenter randomized controlled trial. Annals of Surgery 260 984-992. (doi:10.1097/ SLA.0000000000000794)

Maljaars PW, Peters HP, Mela DJ \& Masclee AA 2008 Ileal brake: a sensible food target for appetite control. A review. Physiology \& Behavior 95 271-281. (doi:10.1016/j.physbeh.2008.07.018)

McGavigan AK, Garibay D, Henseler ZM, Chen J, Bettaieb A, Haj FG, Ley RE, Chouinard ML \& Cummings BP 2015 TGR5 contributes to glucoregulatory improvements after vertical sleeve gastrectomy in mice. Gut [in press]. (doi:10.1136/gutjnl-2015-309871)

Mraz M \& Haluzik M 2014 The role of adipose tissue immune cells in obesity and low-grade inflammation. Journal of Endocrinology 222 R113-R127. (doi:10.1530/joe-14-0283)

Mraz M, Lacinova Z, Kavalkova P, Haluzikova D, Trachta P, Drapalova J, Hanusova V \& Haluzik M 2011 Serum concentrations of fibroblast growth factor 19 in patients with obesity and type 2 diabetes mellitus: the influence of acute hyperinsulinemia, very-low calorie diet and PPAR-alpha agonist treatment. Physiological Research 60 627-636.

Nannipieri M, Baldi S, Mari A, Colligiani D, Guarino D, Camastra S, Barsotti E, Berta R, Moriconi D, Bellini R, et al. 2013 Roux-en-Y gastric bypass and sleeve gastrectomy: mechanisms of diabetes remission and role of gut hormones. Journal of Clinical Endocrinology and Metabolism 98 4391-4399. (doi:10.1210/jc.2013-2538)

O'Rahilly S 1997 Science, medicine, and the future. Non-insulin dependent diabetes mellitus: the gathering storm. BMJ 314 955-959. (doi:10.1136/bmj.314.7085.955)

Patel SR, Mason J \& Hakim N 2012 The duodenal-jejunal bypass sleeve (endobarrier gastrointestinal liner) for weight loss and treatment of type ii diabetes. Indian Journal of Surgery 74 275-277. (doi:10.1007/ s12262-012-0721-3)

Penney NC, Kinross J, Newton RC \& Purkayastha S 2015 The role of bile acids in reducing the metabolic complications of obesity after bariatric surgery: a systematic review. International Journal of Obesity 39 1565-1574. (doi:10.1038/ijo.2015.115)

Pories WJ 2008 Bariatric surgery: risks and rewards. Journal of Clinical Endocrinology and Metabolism 93 S89-S96. (doi:10.1210/jc.2008-1641)

Reaven G, Abbasi F \& McLaughlin T 2004 Obesity, insulin resistance, and cardiovascular disease. Recent Progress in Hormone Research 59 207-223. (doi:10.1210/rp.59.1.207)

Rohde U, Hedback N, Gluud LL, Vilsboll T \& Knop FK 2016 Effect of the endobarrier gastrointestinal liner on obesity and type 2 diabetes: a systematic review and meta-analysis. Diabetes, Obesity \& Metabolism 18 300-305. (doi:10.1111/dom.12603)

Rubino F, Forgione A, Cummings DE, Vix M, Gnuli D, Mingrone G, Castagneto M \& Marescaux J 2006 The mechanism of diabetes control after gastrointestinal bypass surgery reveals a role of the proximal small intestine in the pathophysiology of type 2 diabetes. Annals of Surgery 244 741-749. (doi:10.1097/01.sla.0000224726.61448.1b)

Setchell KD \& Vestal CH 1989 Thermospray ionization liquid chromatography-mass spectrometry: a new and highly specific technique for the analysis of bile acids. Journal of Lipid Research $\mathbf{3 0}$ 1459-1469.

Silva B \& Faustino P 2015 An overview of molecular basis of iron metabolism regulation and the associated pathologies. Biochimica et Biophysica Acta 1852 1347-1359. (doi:10.1016/j.bbadis.2015.03.011)

Sjostrom L, Narbro K, Sjostrom CD, Karason K, Larsson B, Wedel H, Lystig T, Sullivan M, Bouchard C, Carlsson B, et al. 2007 Effects of bariatric surgery on mortality in Swedish obese subjects. New England Journal of Medicine 357 741-752. (doi:10.1056/NEJMoa066254)

Spinelli V, Chavez-Talavera O, Tailleux A \& Staels B 2016 Metabolic effects of bile acid sequestration: impact on cardiovascular risk factors. Current Opinion in Endocrinology, Diabetes, and Obesity 23 138-144. (doi:10.1097/MED.0000000000000235)

Tomlinson E, Fu L, John L, Hultgren B, Huang X, Renz M, Stephan JP, Tsai SP, Powell-Braxton L, French D, et al. 2002 Transgenic mice expressing human fibroblast growth factor-19 display increased metabolic rate and decreased adiposity. Endocrinology 143 1741-1747. (doi:10.1210/endo.143.5.8850)

Ussher JR \& Drucker DJ 2014 Cardiovascular actions of incretin-based therapies. Circulation Research 114 1788-1803. (doi:10.1161/ CIRCRESAHA.114.301958)

Vitek L \& Haluzik M 2016 The role of bile acids in metabolic regulation. Journal of Endocrinology 228 R85-R96. (doi:10.1530/joe-15-0469)

Young A 2005 Inhibition of glucagon secretion. Advances in Pharmacology 52 151-171. (doi:10.1016/S1054-3589(05)52008-8)

Received in final form 21 July 2016

Accepted 29 July 2016

Accepted Preprint published online 29 July 2016 http://joe.endocrinology-journals.org

DOI: 10.1530/JOE-16-0206
๑) 2016 Society for Endocrinology Printed in Great Britain 